\title{
Sleepy genes
}

\section{Bruce F. O'Hara ${ }^{\text {* }}$ and Valérie Mongrain ${ }^{2,3}$}

Department of Biology, University of Kentucky, Lexington, KY, USA

2 Center for Advanced Research in Sleep Medicine, HSCM, Université de Montréal, Montréal, QC, Canada

${ }^{3}$ Department of Psychiatrie, Université de Montréal, Montréal, QC, Canada

*Correspondence: bohara@email.uky.edu

\section{A Commentary on}

Molecular and anatomical signatures of sleep deprivation in the mouse brain

by Carol L. Thompson, Jonathan P. Wisor, Chang-Kyu Lee, Sayan D. Pathak, Dmitry Gerashchenko, Kimberly A. Smith, Shanna R. Fischer, Chihchau L. Kuan, Susan M. Sunkin, Lydia L. Ng, Christopher Lau, Mike Hawrylycz, Allan R. Jones, Thomas Kilduff and Edward S. Lein (2010). Front. Neurosci. doi: 10.3389/fnins.2010.00165.

Sleep has long been linked to recovery and multiple brain functions (Kleitman, 1963). It is now well established that sleep/ wake states are driven by changes in neuronal activity and, measurements of transcriptional expression (i.e., mRNA levels) brought significant contributions to this knowledge. The first consistent evidence came with the observation that immediate early genes (IEGs), such as fos, were activated by wake or sleep deprivation in most brain regions (Pompeiano et al., 1994; Terao et al., 2003). In fact, mRNA levels of fos and other IEGs have long been used as robust markers of neuronal activity in many areas of neuroscience (Morgan and Curran, 1991). Within neurons, IEGs usually increase their expression with increased activity or firing rates. In the field of sleep research, this approach has not only confirmed that most brain areas are somewhat more active during wake, but also found important sleep-active regions such as the ventrolateral preoptic area or VLPO (Sherin et al., 1996). Also, within the cortex, a small subset of neurons expressing $n$ Nos increase their expression of fos during non-REM sleep, and may play important roles in sleep homeostasis (Gerashchenko et al., 2008).

In Thompson et al. (2010), using sophisticated algorithms and high-throughput in situ hybridization (ISH), the authors demonstrated that specific cortical layers and cortical areas may increase or decrease specific IEG mRNAs with sleep/ wake states. Importantly, several conditions were used in this research including normal wakefulness (W), sleep deprivation (SD), SD followed by recovery sleep, and sleep in undisturbed mice. In most previous research, SD was generally considered simply a way to maximize wake (W), and in general, natural periods of $\mathrm{W}$ at night and periods of forced wake during SD had similar increased levels of IEG mRNAs, allaying concerns that the stress of SD might produce gene changes not seen with natural W. However, the improved topographic resolution in this current study shows for the first time that SD and W often have subtle but important differences throughout the cortex, and throughout the brain, suggesting the activation of at least some distinct pathways. This is perhaps not too surprising given that $\mathrm{SD}$ induces stress responses, such as increased corticosterone, and a recent study by one of us (Valerie Mongrain) has found that adrenalectomy reduces or in some cases eliminates the changes in gene expression associated with SD (Mongrain et al., 2010).

In addition to a comprehensive examination of many different IEGs such as Arc, Nr4al, and fos, this article examined 222 other genes that were selected from both the literature and their own detailed microarray study in seven laser dissected brain regions. Microarray studies are often criticized for the lack of follow-up or reproducibility of the hundreds of mRNAs identified to change under the assayed conditions. However, the use of microarrays in the search for sleep related genes has been generally fruitful and reproducible (Mackiewicz et al., 2010; Mongrain et al., 2010). Interestingly, while microarray data indicate that a roughly equal number of genes have their expression increased or decreased by SD, a majority of IEGs show an increase in conditions where waking predominates and, many of these appear to be directly linked to the regulation of neuronal functions during sleep
(Mongrain et al., 2010). In Thompson et al. (2010), the thorough examination of 53 candidates among the 222 targets measured by ISH represents a substantial addition to our knowledge of gene expression changes across SD, sleep, and $\mathrm{W}$, with unprecedented neuroanatomical resolution, including double labeling studies that identified individual neuronal subtypes within which specific groups of IEGs segregate together. For example, sleep/wake-dependent changes in Nts were always found within the same cell type as changes in Nr4a1, whereas changes in Pdyn only partially overlap with those of $\mathrm{Nr} 4 a 1$. Given the proposed role of Nr4a1 in a neuroprotective pathway (Zhang et al., 2009), this finding, along with most other data presented, not only serves sleep research, but many other areas of neuroscience as well.

Similarly, the authors reported that some important changes in transcriptional expression with sleep and wakefulness did not occur in neurons but rather in glial cells (i.e., oligodendrocytes for $S g k$ ). Glia, in particular astrocytes, were reported to contribute to the electroencephalographic hallmark of sleep intensity (Amzica and Massimini, 2002) and, more recently, gliotransmission was directly shown to control both the homeostatic regulation of sleep and the consequences of sleep loss (Halassa et al., 2009). These cell populations, which are predominant in the brain, have been greatly neglected in modeling nervous system functions including sleep. The finding reported by Thompson et al., which needs to be expanded to more glial populations and non-IEGs transcripts as well, highlights the importance of assessing cell-type specific response. High-throughput ISH should be beneficial to tackle this issue.

As the authors noted, this is discovery science, and the results generated more hypotheses than they tested. However, some general observations were clear. For example, data confirmed that the forebrain 
responded more to $\mathrm{W}$ and $\mathrm{SD}$, while the master circadian clock in the hypothalamic SCN exhibited more time of day effects. In general, these data have a great potential to impact sleep research by providing a detailed topographical framework for the molecular changes associated with sleep, $\mathrm{SD}$, natural wake, and time of day effects on the brain. This should not only guide future studies on the role of sleep for various brain functions but also help unravel critical aspects of nervous system functioning given that sleep loss impairs fundamental neuronal functions such as neuroplasticity and neurogenesis (Meerlo et al., 2009; Tononi, 2009).

\section{REFERENCES}

Amzica, F., and Massimini, M. (2002). Glial and neuronal interactions during slow wave and paroxysmal activities in the neocortex. Cereb. Cortex 12, 1101-1113.

Gerashchenko, D., Wisor, J. P., Burns, D., Reh, R. K., Shiromani, P. J., Sakurai, T., de la Iglesia, H. O., and Kilduff, T. S. (2008). Identification of a population of sleep-active cerebral cortex neurons. Proc. Natl. Acad. Sci. U.S.A. 105, 10227-10232.

Halassa, M. M., Florian, C., Fellin, T., Munoz, J. R., Lee, S. Y., Abel, T., Haydon, P. G., and Frank, M. G.
(2009). Astrocytic modulation of sleep homeostasis and cognitive consequences of sleep loss. Neuron 61, 213-219.

Kleitman, N. (1963). Sleep and Wakefulness. Chicago: The University of Chicago Press.

Mackiewicz, M., Zimmerman, J. E., Shockley, K. R., Churchill, G. A., and Pack, A. I. (2010). What are microarrays teaching us about sleep? Trends Mol. Med. 15, 79-87.

Meerlo, P., Mistlberger, R. E., Jacobs, B. L., Heller, H. C., and McGinty, D. (2009). New neurons in the adult brain: the role of sleep and consequences of sleep loss. Sleep Med. Rev. 13, 187-194.

Mongrain, V., Hernandez, S., Pradervand, S., Dorsaz, S., Curie, T., Hagiwara, G., Gip, P., Heller, H. C., and Franken, P. (2010). Separating the contribution of glucocorticoids and wakefulness to the electrophysiological and molecular correlates of sleep homeostasis. Sleep 33, 1147-1157.

Morgan, J. I., and Curran, T. (1991). Stimulustranscription coupling in the nervous system: involvement of the inducible proto-oncogenes fos and jun. Annu. Rev. Neurosci. 14, 421-451.

Pompeiano, M., Cirelli, C., and Tononi, G. (1994). Immediate-early genes in spontaneous wakefulness and sleep: expression of c-fos and NGFI-A mRNA and protein. J. Sleep Res. 3, 80-96.

Sherin, J. E., Shiromani, P. J., McCarley, R. W., and Saper, C. B. (1996). Activation of ventrolateral preoptic neurons during sleep. Science 271, 216-219.

Terao, A., Greco, M. A., Davis, R. W., Heller, H. C., and Kilduff, T. S. (2003). Region-specific changes in immediate early gene expression in response to sleep deprivation and recovery sleep in the mouse brain. Neuroscience 120, 1115-1124.

Thompson, C. L., Wisor, J. P., Lee, C. K., Pathak, S. D., Gerashchenko, D., Smith, K. A., Fischer, S. R., Kuan, C. L., Sunkin, S. M., Ng, L. L., Lau, C., Hawrylycz, M., Jones, A. R., Kilduff, T. S., and Lein, E. S. (2010). Molecular and anatomical signatures of sleep deprivation in the mouse brain. Front. Neurosci. doi: 10.3389/ fnins.2010.00165.

Tononi, G. (2009). Slow wave homeostasis and synaptic plasticity. J. Clin. Sleep Med. 15 (2 Suppl), S16-S19.

Zhang, S. J., Zou, M., Lu, L., Lau, D., Ditzel, D. A., Delucinge-Vivier, C., Aso, Y., Descombes, P., and Bading, H. (2009). Nuclear calcium signaling controls expression of a large gene pool: identification of a gene program for acquired neuroprotection induced by synaptic activity. PLoS Genet. 5, e1000604. doi: 10.1371/journal.pgen.1000604.

Received: 11 September 2010; accepted: 08 October 2010; published online: 01 November 2010.

Citation: O'Hara BF and Mongrain V (2010). Sleepy molecules. Front. Neurosci. 4:183. doi: 10.3389/ fnins.2010.00183

This article was submitted to Frontiers in Neurogenomics, a specialty of Frontiers in Neuroscience.

Copyright (C) 2010 O'Hara and Mongrain. This is an open-access article subject to an exclusive license agreement between the authors and the Frontiers Research Foundation, which permits unrestricted use, distribution, and reproduction in any medium, provided the original authors and source are credited. 